\title{
An Experimental Study of the Effect of Current THD to kWh Meter's Energy Measurement
}

\author{
Syafrudin Masri', M.N. Mamat' ${ }^{2}$ M.Y. Yahya ${ }^{3}$ \\ Associate Professor, PPKEE, Universiti Sains Malaysia, Penang, Malaysia ${ }^{1}$ \\ Senior Research Officer, PPKEE, Universiti Sains Malaysia, Penang, Malaysia ${ }^{2}$ \\ Research Assistant, PPKEE, Universiti Sains Malaysia, Penang, Malaysia ${ }^{3}$
}

\begin{abstract}
An experimental study of the effect of constant rms current with different THD to the single phase digital $\mathrm{kWh}$ meter is presented in this paper. The study focused on how harmonics from non-linear load with constant voltage supply and constant rms current affect the energy measurement of single phase digital watt-hour meter. Traditionally, analog electromechanical meter is using the rms current as its main measurement parameter. In digital meter, different techniques and sampling are used to measure the power consumed by the consumers. Although different techniques and sampling are used, the rms current parameter is still the dominant parameter used to measure and calculate the energy measurement. Both electromechanical and digital meter show good measurements under linear load condition. On the other hand, under non-linear load, harmonics are often neglected in energy measurement. In addition, harmonics in heavily distorted current originated from non-linear load and contributed to lot of losses and it will not be recorded in the billing. To make the situation worse, harmonics can propagate through the transformer and they will be affected the power network either if the harmonics are injected from the source or load side. Analysis from the measurement data clearly showed the effect of the harmonics to the energy measurement. In consequence, either utility company or consumer shall be affected if the harmonics parameter is neglected in the energy measurement purpose. The results showed that no significant difference when the actual digital watt-hour meter energy reading is compared to the calculated energy consumption based on rms current value. Therefore, either harmonics are taken or not taken into account during the energy measurement, the consumer is not affected and still paying the same prices. However, the utility company will be burdened by some losses if harmonics are not taken into consideration.
\end{abstract}

Keywords: Non linear load, THD current, Real power, Energy, Billing and kWh meter-EDS2560.

\section{INTRODUCTION}

In modern electrical distribution system, there have been also lead to more distortions in the power network. sudden increases of non-linear loads such as power supply According to the Electric Power Research (EPR), in 2012 rectified equipments, new switched mode power supply an estimated of $85 \%$ of all electric power flows through appliances, domestic appliances and adjustable speed drive electronic converters. All these devices are named as noncontrol equipments. Non-linear load in a power system is linear loads and become sources of harmonics [2].

characterized by the introduction of a switching action and The amplitude and phase angle of a harmonic is dependent consequently current interruptions. This behaviour on the circuit and on the load it drives. The harmonic provides current with different components that are currents flow toward the power source through the path of multiples of the fundamental frequency of the system. These components are called harmonics. These are the loads which have non-linear characteristics and result in harmonic distortion of both voltage and current waveforms. As more non-linear loads are introduced within a facility, these waveforms get more distorted [1-6]. Higher distortion levels can affect the performance of electrical energy metering equipment and therefore impact the billing charges of the utility company. In addition, harmonics result in extra losses in power distribution system such as transformers and capacitors bank [2]. Moreover, the changes in the operating condition and the rapid growth of advanced power conversion devices, electronic equipments, computers, office automation, airconditioning systems, adjustable speed heating ventilation the least impedance and presented by this equation.

$I_{s}(t)=I_{m 1} \sin \omega t+I_{m_{2}} \sin 2 \omega t+I_{m_{3}} \sin 3 \omega t+\ldots+I_{m n} \sin n \omega t$

where

$(t)=$ Instantaneous current

$I_{m 1}=$ First max harmonic current

$n \quad=$ Order of harmonic

Total harmonic distortion (THD) is an amplifier or preamplifier specification that compares the output signal of the amplifier with the input signal and measures the level differences in harmonic frequencies between the two. The difference is called total harmonic distortion. THD applies to both current and voltage and is defined as the root mean square (rms) summation value of harmonics divided by the 
rms value of the fundamental, and then multiplied by $100 \%$ and defined as:

$$
\mathrm{THD}=\frac{A_{\text {dis }}}{A_{1}} * 100 \%
$$

where;

$\mathrm{A}_{\mathrm{dis}}=$ rms summation of current or voltage distortion

$A_{1}=$ rms value of the fundamental current or voltage

THD of voltage (THDs) is usually less than 5\%. THDs below $5 \%$ are widely considered to be acceptable, but values above $10 \%$ are definitely unacceptable and will cause problems for sensitive equipment and loads [4]. THD of current (THDi) is the total harmonic distortion of the load current. THDi varies from a few percent to more than $100 \%$. It deteriorates the power factor of the system, which is the ratio between the average power of a certain load and the average power calculated for a pure resistive load with equal voltage amplitude.

\section{MEASUREMENT SETUP}

Measurements were conducted to an adjustable non-linear load powered by an adjustable low distorted voltage power supply. Power supply was set to $240 \mathrm{~V}$ single phase, $50 \mathrm{~Hz}$. It was assumed that this power supply will not contributed any harmonics into the measurement setup. The non-linear load consisted of one set of variable capacitors, one set of high power variable resistors and a full bridge rectifier to perform the AC-DC conversion. Variable capacitors were used to set different THDi during measurement while variable resistors were used to set the constant rms current. The rms current was set to a constant value of 9.60A.

Data were measured using Fluke 43B Power Quality Analyzer at the non-linear load to record all prominent parameters. The parameters were used to measure and calculate the total electrical energy consumption from the load side. EDS2560 single phase digital watt-hour meter was used to measure the real-time energy consumption. It was placed directly after the incoming mains connection. Fig. 1 shows the measurement setup.

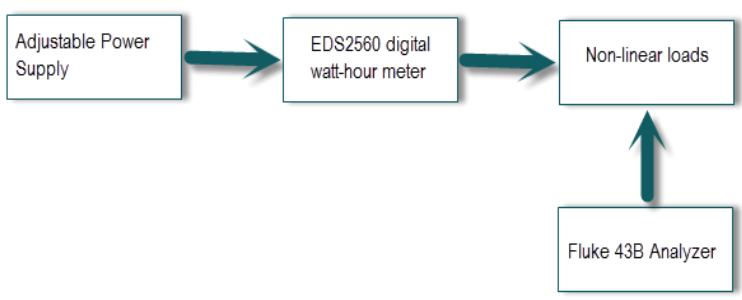

Fig. 1 Measurement Setup

Fluke 43B Analyzer was used to record the rms current, fundamental current, power factor, THDi and individual harmonics. EDS2560 digital meter was used to record the actual meter reading during measurement setup. A series audit of measurement and monitoring for all parameters above were carried out for eight different THDi. For each THDi, EDS2560 measured the energy usage within 24 hours, $\mathrm{E}_{\mathrm{p}}(\mathrm{kWh})$.
The energy consumed for 24 hours from Fluke 43B can be divided into three types namely energy consumed based on rms current, $E_{\mathrm{rms}}(\mathrm{kWh})$, energy consumed based on fundamental current, $\mathrm{E}_{\mathrm{f}}(\mathrm{kWh})$ and energy consumed based on effective harmonic current, $\mathrm{E}_{\mathrm{e}}(\mathrm{kWh})$.

All parameters measured and calculated were labeled as follows:

$E_{p}=E D S 2560$ energy measurement for 24 hours in $\mathrm{kWh}$

$\mathrm{E}_{\mathrm{rms}}=$ Fluke $43 \mathrm{~B}$ energy usage for 24 hours using rms current in $\mathrm{kWh}$

$\mathrm{E}_{\mathrm{f}}=$ Fluke 43B energy usage for 24 hours using fundamental current in $\mathrm{kWh}$

$E_{e}=$ Fluke $43 B$ energy usage for 24 hours using effective harmonic current in $\mathrm{kWh}$

$\mathrm{PF}=$ power factor of the non-linear load

$I_{\mathrm{rms}}=\mathrm{rms}$ current in Ampere

$\mathrm{I}_{\mathrm{e}}=$ total effective harmonic current in Ampere

$I_{1}=$ fundamental harmonic current in Ampere

An easy way to comply with the conference paper formatting requirements is to use this document as a template and simply type your text into it.

\section{III.RESULTS AND ANALYSIS}

Table 1 shows the measurement results when the nonlinear load is subjected to different current total harmonic distortion, THDi $(\%)$. As stated earlier, power supply, $\mathrm{V}_{\mathrm{s}}(\mathrm{V})$ is set at $240 \mathrm{~V}, 50 \mathrm{~Hz}$ while rms current, $\mathrm{I}_{\mathrm{rms}}(\mathrm{A})$ is set at 9.6A. EDS2560 measures the energy consumed within 24 hours. Other parameters recorded are fundamental harmonic current, $\mathrm{I}_{1}(\mathrm{~A})$, power factor $(\mathrm{PF})$.

From the Table 1, PF is affected by the THDi. Clearly, PF is decreased when the THDi is increased.

Table 1 Parameters for constant rms current for energy consumed measured using EDS2560

\begin{tabular}{|c|c|c|c|}
\hline THDi & $\mathrm{I}_{1}$ & $\mathrm{PF}$ & $\mathrm{E}_{\mathrm{p}}$ \\
\hline 0.9 & 9.60 & 1.00 & 53.89 \\
\hline 9.6 & 9.57 & 0.96 & 52.66 \\
\hline 11.5 & 9.53 & 0.95 & 51.77 \\
\hline 14.2 & 9.50 & 0.94 & 51.02 \\
\hline 17.7 & 9.43 & 0.92 & 50.68 \\
\hline 20.7 & 9.40 & 0.90 & 50.55 \\
\hline 26.5 & 9.23 & 0.87 & 49.14 \\
\hline 36.5 & 8.95 & 0.81 & 44.56 \\
\hline
\end{tabular}

Fig. 2 shows the current and voltage waveforms when the non-linear load is subjected to different THDi. In this setup, the power supply voltage retains the pure sinusoidal shape even under heavy distortion whereas current waveform shows a distorted sinusoidal shape.

Table 2 shows the harmonic spectrums when different THDi is applied to the non-linear load. Heavier THDi leads to lower fundamental current and higher value to the other harmonics current. 


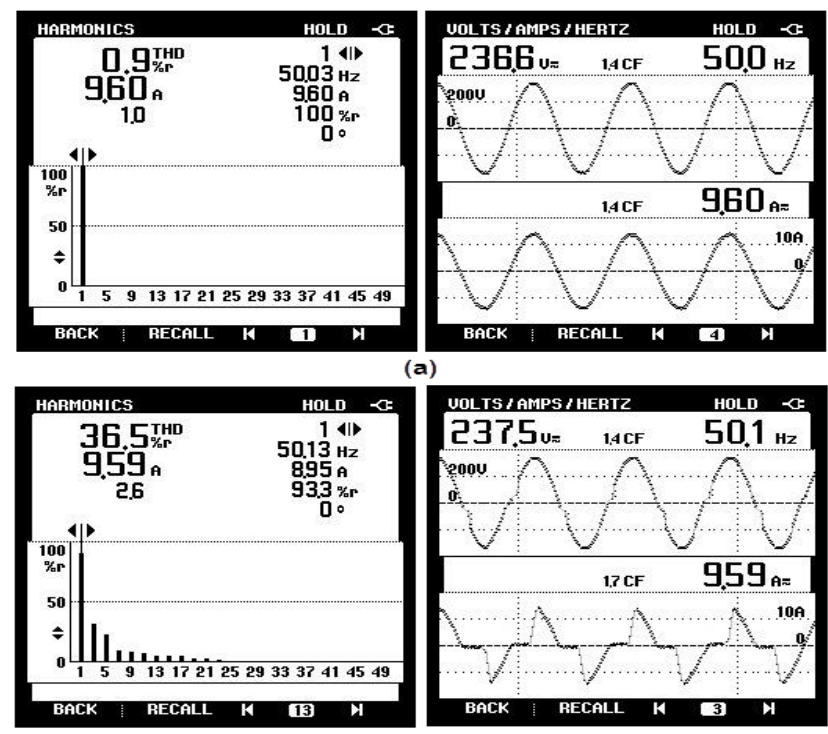

(b)

Fig. 2 (a) Voltage and rms current under linear load condition (b) Voltage and rms current under non-linear load with heavy THDi condition

Table 2 The harmonic spectrum for different THDi for constant rms current

\begin{tabular}{|l|l|l|l|l|l|l|l|l|}
\hline THDi & $\mathrm{I}_{1}$ & $\mathrm{I}_{3}$ & $\mathrm{I}_{5}$ & $\mathrm{I}_{7}$ & $\mathrm{I}_{9}$ & $\mathrm{I}_{11}$ & $\mathrm{I}_{13}$ & $\mathrm{I}_{15}$ \\
\hline 0.9 & 9.60 & 0.00 & 0.00 & 0.00 & 0.00 & 0.00 & 0.00 & 0.00 \\
\hline 9.6 & 9.57 & 0.46 & 0.39 & 0.26 & 0.39 & 0.28 & 0.25 & 0.13 \\
\hline 11.5 & 9.53 & 0.58 & 0.49 & 0.34 & 0.45 & 0.30 & 0.28 & 0.13 \\
\hline 14.2 & 9.50 & 0.78 & 0.64 & 0.42 & 0.52 & 0.32 & 0.29 & 0.16 \\
\hline 17.7 & 9.43 & 1.05 & 0.83 & 0.51 & 0.56 & 0.31 & 0.31 & 0.23 \\
\hline 20.7 & 9.40 & 1.32 & 1.00 & 0.57 & 0.57 & 0.30 & 0.37 & 0.30 \\
\hline 26.5 & 9.23 & 1.84 & 1.22 & 0.60 & 0.58 & 0.41 & 0.47 & 0.40 \\
\hline 36.5 & 8.95 & 2.78 & 1.50 & 0.69 & 0.67 & 0.59 & 0.45 & 0.59 \\
\hline
\end{tabular}

Table 3 shows the total effective harmonics current, $I_{e}$ Fig 3. shows the comparison for the rms, fundamental and compared to the constant rms current, $\mathrm{I}_{\mathrm{rms}}$ and fundamental total effective harmonics current under different THDi. harmonic current, $I_{1}$. In order to calculate $I_{e}$, the harmonics From the graph, THDi contributes significant effect to the sequences must be observed to get the correct effective fundamental and effective harmonics current. Comparing value. The sequences are as follows.

Zero sequence: $3,6,9,12,15 \ldots$

Positive sequence: $1,4,7,10,13 \ldots$

Negative sequence: $2,5,8,11,14 \ldots$

Hence, $\mathrm{I}_{\mathrm{e}}=\mathrm{I}_{1}-\mathrm{I}_{5}+\mathrm{I}_{7}-\mathrm{I}_{11}+\mathrm{I}_{13}$

Table 3 Total effective harmonics current of a constant rms current under different THDi

\begin{tabular}{|c|c|c|c|}
\hline THDi & $\mathrm{I}_{\mathrm{rms}}$ & $\mathrm{I}_{1}$ & $\mathrm{I}_{\mathrm{e}}$ \\
\hline 0.9 & 9.60 & 9.60 & 9.60 \\
\hline 9.6 & 9.60 & 9.57 & 9.41 \\
\hline 11.5 & 9.60 & 9.53 & 9.36 \\
\hline 14.2 & 9.60 & 9.50 & 9.25 \\
\hline 17.7 & 9.60 & 9.43 & 9.11 \\
\hline 20.7 & 9.60 & 9.40 & 9.04 \\
\hline 26.5 & 9.60 & 9.23 & 8.67 \\
\hline 36.5 & 9.60 & 8.95 & 8.00 \\
\hline
\end{tabular}
rms value and the effective current, it is clear that the THDi affects the value of the effective current under nonlinear load. The heavier the THDi, the lower the effective current is. The same pattern also applies to the fundamental current. The heavier the THDi, the lower the fundamental current is.

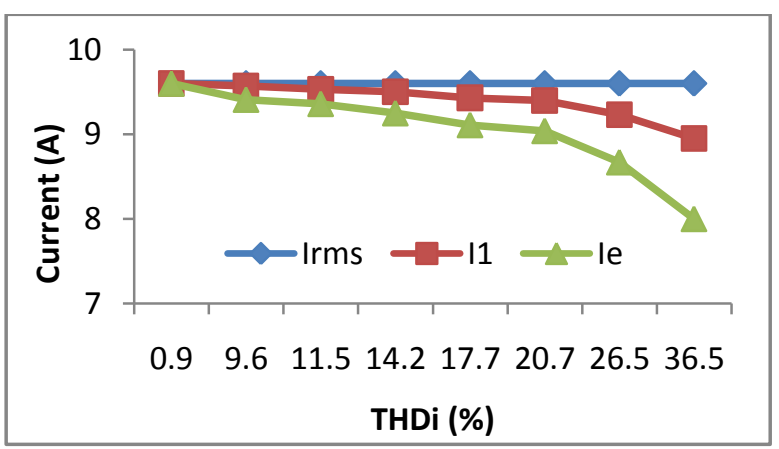

Fig. 3 Different current types under different THDi 
Vol. 5, Issue 2, February 2017

Table 4 shows the comparison between the energy As a result, the utility company will be losing more when measurement from EDS2560 and the energy usage from the consumer uses moderate or heavy THDi load. From Fluke 43B based on rms current, fundamental harmonic the graph, THDi more than $15 \%$ will significantly affected current and effective harmonic current. Relatively, $\mathrm{E}_{\mathrm{rms}}$ the utility company losses.

shows a quite similar value compared to the measured $\mathrm{E}_{\mathrm{p}}$.

Table 4 Energy consumption of the non-linear load with different current types

\begin{tabular}{|c|c|c|c|c|}
\hline THDi & $\mathrm{E}_{\mathrm{p}}$ & $\mathrm{E}_{\mathrm{rms}}$ & $\mathrm{E}_{\mathrm{f}}$ & $\mathrm{E}_{\mathrm{e}}$ \\
\hline 0.9 & 53.89 & 55.30 & 55.30 & 55.30 \\
\hline 9.6 & 52.66 & 53.08 & 52.92 & 52.03 \\
\hline 11.5 & 51.77 & 52.53 & 52.15 & 51.22 \\
\hline 14.2 & 51.02 & 51.98 & 51.44 & 50.08 \\
\hline 17.7 & 50.68 & 50.87 & 49.97 & 48.28 \\
\hline 20.7 & 50.55 & 49.77 & 48.73 & 46.86 \\
\hline 26.5 & 49.14 & 48.11 & 46.25 & 43.45 \\
\hline 36.5 & 44.56 & 44.79 & 41.76 & 37.32 \\
\hline
\end{tabular}

Fig. 4 shows the graphical energy consumption with different current types under different THDi. Comparing the actual reading based on EDS2560 to the other readings, clearly the most suitable parameter to be used in the digital watt-hour energy measurement is the rms current. No significant difference between the $E_{p}$ and the $E_{r m s}$ value is spotted when comparing both parameters. However, fundamental and effective harmonic current show significant differences when they are compared to the measured EDS2560 values.

From the consumer side, the non-linear load (even with heavy THDi) did not influence the customer's bill for single phase usage because the measured and the calculated energy consumption did not show any huge differences. However, from the utility company side, it will be affected by the non-linear load because the harmonics are not considered in the energy consumption for the digital watt-hour single phase meter measurement.

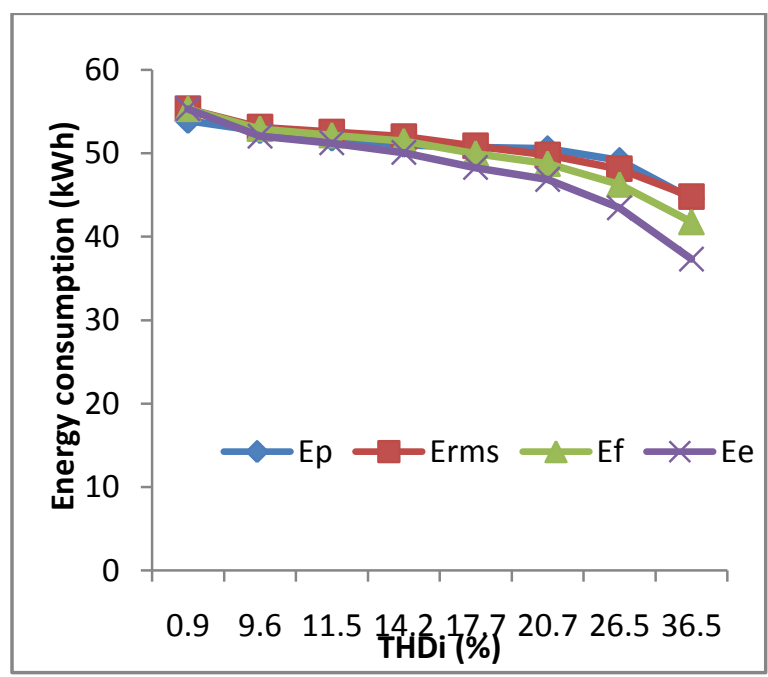

Fig 4. Energy consumption with different current types under different THDi

\section{IV.CONCLUSION}

Digital watt-hour meter is widely used to replace the conventional electromechanical analog meter to measure the energy consumption by the customer. Although the technique to measure energy consumption for this digital watt-hour meter is totally different compared to the analog meter, coincidently this meter also has the same problem with the analog meter. This digital meter also cannot measure accurately the energy consumption from the nonlinear load especially when moderate to heavy distortion is subjected to it.

RMS current is still the main parameter used to measure the energy consumption in the digital meter. Although THDi did not influence the consumer's energy bill but the utility company will bear the losses when the harmonics are not taken into account. However, if THDi needs to be considered in the energy consumption billing, the bill tariff should be tailored accordingly to include the distortion into account.

\section{ACKNOWLEDGMENT}

The work described in this paper was fully supported by a grant from Universiti Sains Malaysia (Grant no. 1001/PELECT/814252).

\section{REFERENCES}

1] C. Venkatesh, D. S. K., D.V.S.S. Siva Sarma, M. Sydulu (2008). "Modelling of Nonlinear Loads and Estimation of Harmonics in Industrical Distribution System." Fifteenth National Power System Conference (NPSC), IIT.

[2] A.Priyadharshini, N. D., AR.Uma saranya, R.Anit (2012). "Survey of Harmonics in Non Linear Loads." International Journal of Recent Technology and Engineering (IJRTE) Volume-1(Issue 1): 6.

[3] Shmilovitz, D. (2005). "On the Definition of Total Harmonic Distortion and Its Effect on Measurement Interpretation." IEEE Transactions On Power Delivery Vol. 20(No. 1): 3.

[4] W. Mack Grady, S. S. (20011). "Understanding Power System Harmonics." Ieee Power Eng. Rev. 21: 3.

[5] Indrajit Pukrayastha, P. J. S. (1990). "Effect of Harmonics on Power Measurement." Transactions On Industry Applications: 3.

[6] R. M. H. E. E. D. Prof. Ahmed A. Hossam-Eldin, Alexandria University Alexandria, Egypt, "Study of The Effect of Harmonics On Measurements of The Energy Meters," presented at the Power Systems Conference, 2006. MEPCON 2006. Eleventh International Middle East, El-Minia, 2006.

\section{BIOGRAPHIES}

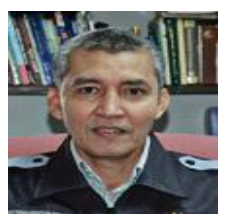

Syafrudin Masri received the M.Sc. degree in electrical engineering and the Ph.D. degree in electrical engineering from the Institut Teknologi Bandung, Indonesia in 1992 and 2000 
respectively. Currently, he is an associate professor in the electrical and electronic department Universiti Sains Malaysia. He was the electrical engineering program chairman from 2006 to 2015. His research interests cover the power quality, power system, electrical machines and drives and also renewable energy systems.

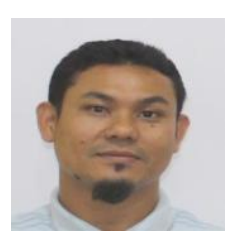

Mohd Nadzri Mamat received the M.Sc. degree in electrical engineering from the Universiti Sains Malaysia in 2010. Currently, he is a senior research officer in the electrical and electronic department Universiti Sains Malaysia. His research interests cover the design and analysis of various electrical machines, power system, energy conversion and also renewable energy systems.

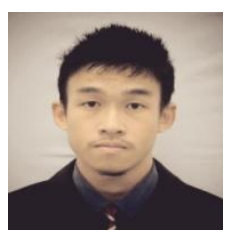

Mohd Yuzair Yahya received the Bachelor degree in electrical engineering from the Universiti Sains Malaysia in 2015. His research interests are in power quality and renewable energy. 